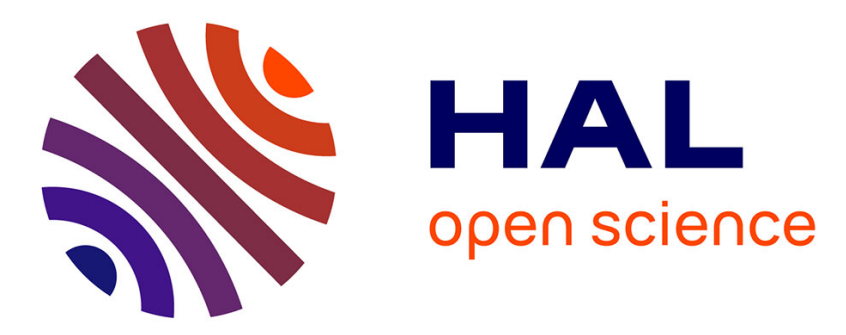

\title{
Damage investigation in CFRP composites using full-field measurement techniques: combination of digital image stereo-correlation, infrared thermography and X-ray tomography
}

Cristina Goidescu, Hélène Welemane, Christian Garnier, Marina Fazzini, Romain Brault, Elodie Péronnet, Sébastien Mistou

\section{To cite this version:}

Cristina Goidescu, Hélène Welemane, Christian Garnier, Marina Fazzini, Romain Brault, et al.. Damage investigation in CFRP composites using full-field measurement techniques: combination of digital image stereo-correlation, infrared thermography and X-ray tomography. Composites Part B: Engineering, 2013, vol. 48, pp. 95-105. 10.1016/j.compositesb.2012.11.016 . hal-00840547

\section{HAL Id: hal-00840547 \\ https://hal.science/hal-00840547}

Submitted on 2 Jul 2013

HAL is a multi-disciplinary open access archive for the deposit and dissemination of scientific research documents, whether they are published or not. The documents may come from teaching and research institutions in France or abroad, or from public or private research centers.
L'archive ouverte pluridisciplinaire HAL, est destinée au dépôt et à la diffusion de documents scientifiques de niveau recherche, publiés ou non, émanant des établissements d'enseignement et de recherche français ou étrangers, des laboratoires publics ou privés. 


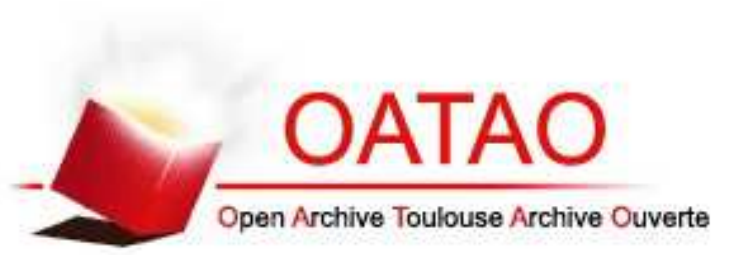

\section{Open Archive Toulouse Archive Ouverte (OATAO)}

OATAO is an open access repository that collects the work of Toulouse researchers and makes it freely available over the web where possible.

This is an author-deposited version published in: http://oatao.univ-toulouse.fr/ Eprints ID: 8854

To link to this article: DOI:10.1016/j.compositesb.2012.11.016 URL: http://dx.doi.org/10.1016/j.compositesb.2012.11.016

To cite this version: Goidescu, Cristina and Welemane, Hélène and Garnier, Christian and Fazzini, Marina and Brault, Romain and Péronnet, Elodie and Mistou, Sébastien Damage investigation in CFRP composites using full-field measurement techniques: combination of digital image stereo-correlation, infrared thermography and Xray tomography. (2013) Composites Part B: Engineering, vol. 48 . pp. 95-105. ISSN 1359-8368

Any correspondence concerning this service should be sent to the repository administrator: staff-oatao@ listes-diff.inp-toulouse.fr 


\title{
Damage investigation in CFRP composites using full-field measurement techniques: Combination of digital image stereo-correlation, infrared thermography and X-ray tomography
}

\author{
Cristina Goidescu ${ }^{\mathrm{a}}$, Hélène Welemane ${ }^{\mathrm{a}, *}$, Christian Garnier ${ }^{\mathrm{a}}$, Marina Fazzini ${ }^{\mathrm{a}}$, Romain Brault ${ }^{\mathrm{a}, \mathrm{b}}$, \\ Elodie Péronnet ${ }^{\mathrm{a}}$, Sébastien Mistou ${ }^{\mathrm{a}, \mathrm{b}}$ \\ a Université de Toulouse, INP/ENIT, LGP EA 1905, 47, Avenue d'Azereix, F-65013 Tarbes, France \\ ${ }^{\mathrm{b}}$ NIMITECH ETUDES, 33, Avenue du Général Leclerc, F-65200 Bagnères-de-Bigorre, France
}

Keywords:

A. Polymer-matrix composites (PMCs)

A. Laminates

B. Optical techniques

Damage

\begin{abstract}
A B S T R A C T
The present work is devoted to damaging process in carbon-fiber reinforced laminated composites. An original experimental approach combining three optical measurement techniques is presented. Image stereo-correlation and infrared thermography, that respectively provide the kinematic and thermal fields on the surface of the composites, are used in live recording during axis and off-axis tensile tests. Special attention is paid to simultaneously conduct these two techniques while avoiding their respective influence. On the other hand, X-ray tomography allows a post-failure analysis of the degradation patterns within the laminates volume. All these techniques are non-destructive (without contact) and offer an interesting full-field investigation of the material response. Their combination allows a coupled analysis of different demonstrations of same degradation mechanisms. For instance, thermal events and densimetric fields show a random location of damage in the early stages of testing. The influence of the material initial anisotropy on damage growth, localization and failure mode can also be clearly put in evidence through various data. In addition to such characterization, this study illustrates at the same time the capabilities of the different full-field techniques and the damage features they can best capture respectively.
\end{abstract}

\section{Introduction}

An important literature is devoted to the experimental study of damage in Carbon Fiber Reinforced Plastics (CFRP). Many existing works based on direct microscopic observations have identified the degradation mechanisms involved (matrix cracking, fiber failures, fiber-matrix debonding or delamination; see Ladevèze et al. [1]). Generally speaking, the emphasis is put on the macroscopic consequences of these phenomena through the analysis of the damage-induced behavior. In addition to conventional straingauge data, some studies rely for instance on acoustic emissions monitoring [2,3], ultrasonic inspection [4,5], electrical resistance measurements $[6,7]$, and even fiber sensors data $[8,9]$.

All these widespread techniques have allowed considerable progress in the evidence and understanding of damage process. Yet, they generally suffer from artefacts or influences due to the

\footnotetext{
* Corresponding author. Tel.: +33 (0)5 624429 47; fax: +33 (0)5 62442708. E-mail address: Helene.Welemane@enit.fr (H. Welemane).
}

specific preparation needed (sample cutting, surface polishing, gauge gluing, etc.). Moreover, measures obtained represent a local indication (at the sensor position) of the material behavior. New approaches based on optical techniques do not require contact operation and provide full-field measurements that are much more representative of the overall response [10]. Therefore, their use for the detection and analysis of damage in advanced materials such as composites is of crucial interest. Recent developements and improvements of acquisition systems and image processing also make these techniques more accessible for experimental mechanics.

Basically, three kinds of full-field measurements are particularly relevant to address such issue and capture the physical mechanisms involved: kinematic, temperature and density fields. First two are measured on the surface of samples whereas last one is accessible within their volume. In the literature, these data have already been used for the analysis of composites degradation. For instance, kinematic fields are employed for the study of damageinduced displacement/strain heterogeneities [11,12]; examination of thermal fields and heat dissipation allows a non-destructive 
evaluation of internal defects and the monitoring of damage initiation and propagation $[13,14]$; the knowledge of the volume density distribution finally provides the debonding zones within the material $[15,16]$. Yet, in the context of polymeric composite materials, each family of full-field data still remains used separately from the other. Indeed, the association of two of them (generally kinematic and thermal fields) has only been implemented to study the plastic response of metallic materials (see for instance Bodelot et al. [17], Dumoulin et al. [18]).

This paper presents an experimental investigation that combines three full-field measurements (kinematic, thermal and densimetric). Compared to conventional analyses, the aim here is to highlight various, and possibly same, demonstrations of damaging process through different data. Precisely, damage growth in carbon-epoxy laminates submitted to axis and off-axis tensile monotonic tests is addressed in this work. Kinematic and thermal fields are measured simultaneously and live monitoring during the tests. Accordingly, specific experimental device and conditions have been required to avoid the influence of their individual acquisition. Especially, Digital Image Stereo-Correlation (DISC) technique has been used to get the displacements/strains fields on the sample surface in the presence of the thermographic camera. After the failure point, a volumetric analysis using X-ray tomography provides the density distribution within the material. The coupled analysis of different kinds of indicators offers new perspectives for the study of deformation and damage mechanisms. Indeed, it is interesting to face kinematic, thermal and densimetric fields and compare the damage-induced heterogeneities in their respective data. Especially, we show that results are affected by the orientation of the load with the composite structural anisotropy. Meanwhile, this study puts in evidence the capabilities of each full-field technique to capture the different features of the damage process in CFRP (damage growth, localization, failure).

The paper is organized as follows. The carbon-epoxy laminates and loading conditions are described in Section 2. Section 3 presents the general principles and implementing steps of the optical methods. Note that cautions needed for the proper acquisition of each technique are detailed both in Sections 2 and 3. The last part (Section 4) provides experimental results and illustrates the interest of the combined full-field analysis; discussions on the methods acquisition limits are developed throughout this section.

\section{Materials and loading conditions}

\subsection{Carbon-epoxy laminates}

The material of interest is a fiber-reinforced laminated composite with aviation standard approved components: epoxy thermosetting resin HexFlow ${ }^{\circledR}$ RTM 6 and carbon fibers Tenax ${ }^{\circledR}$ HTA40 put into woven Satin 5 pattern called HexForce ${ }^{\circledR}$ G0926. Some physical and mechanical properties of these components are given on Table 1. Laminates have been manufactured by means of Liquid Resin Infusion process at the Composites Research Center of Tarbes. They are composed of 6-plies lay-up $[0 / 90]_{6}$, corresponding to a global thickness of $2 \mathrm{~mm}$. Resulting volume fiber ratio stands around $60 \%$ and the material porosity is less than $3 \%$.

Table 1

Properties of the laminate components (axial mechanical data for fibers).

\begin{tabular}{|c|c|c|}
\hline & Resin HexFlow ${ }^{\circledR}$ RTM 6 & Carbon fibers Tenax ${ }^{\circledR}$ HTA 40 \\
\hline Density & 1.1 & 1.76 \\
\hline Young modulus (MPa) & 2890 & 238,000 \\
\hline Yield stress (MPa) & 75 & 3950 \\
\hline Yield strain (\%) & 3.4 & 1.7 \\
\hline
\end{tabular}

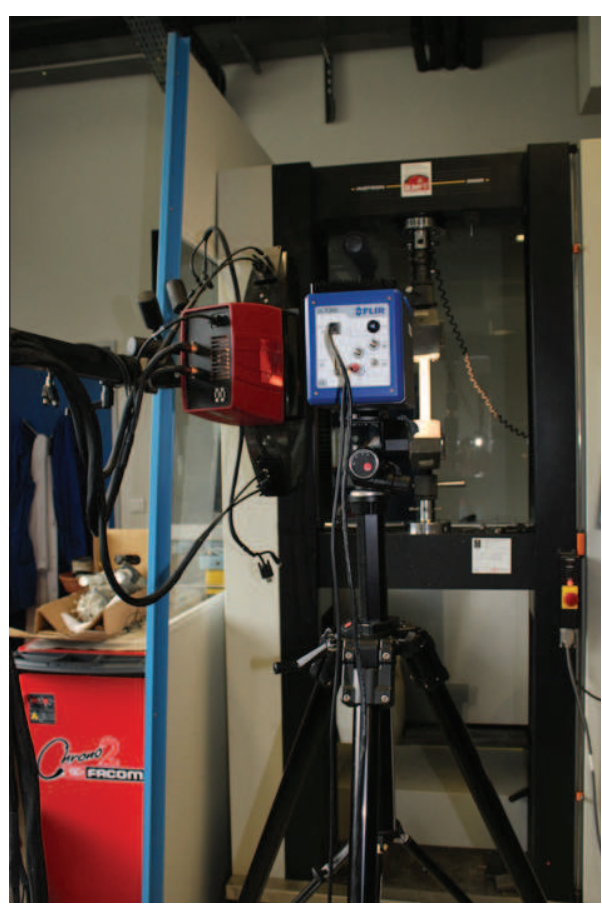

Fig. 1. Experimental set-up.

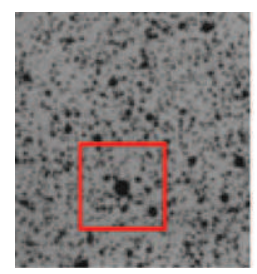

(a) reference state

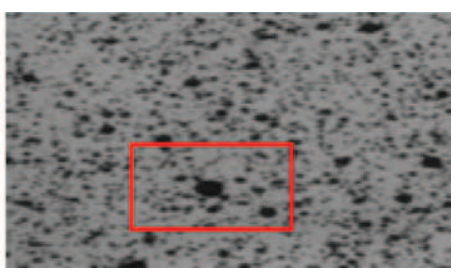

(b) deformed state
Fig. 2. DIC technique [22].

According to standard rules for tensile tests on plastic composites, rectangular samples with pasted glass-epoxy heels have been cut from bigger plates. Their dimensions are $250 \mathrm{~mm}$ length, $25 \mathrm{~mm}$ width with heels of $50 \mathrm{~mm}$ length. The cutting direction has allowed to consider two loading directions for the material, namely:

- type A samples with lay-up [0/90] (axis loading),

- type B samples with lay-up $[ \pm 45]_{6}$ (off-axis loading).

Considering the orthonormal basis $(\mathbf{x}, \mathbf{y}, \mathbf{z})$ of $\mathbb{R}^{3}$, note that the frame $(\mathbf{x}, \mathbf{y})$ corresponds in what follows to the laminates plane and the direction $\mathbf{y}$ to the axial tensile load.

\subsection{Loading conditions}

Tensile mechanical tests were carried out in the Engineering Center of Mechanics, Materials and Surfaces of the National Engineering School of Tarbes with an INSTRON ${ }^{\circledR}$ computer-controlled testing machine (100 kN load cell, Fig. 1). For type A samples, the loading speed is conventionally equal to $2 \mathrm{~mm}$ per minute; for type B samples, it should be $2 \mathrm{~mm}$ per minute up to $2 \%$ of axial strain and then $10 \mathrm{~mm}$ per minute until failure. In addition to monotonic 


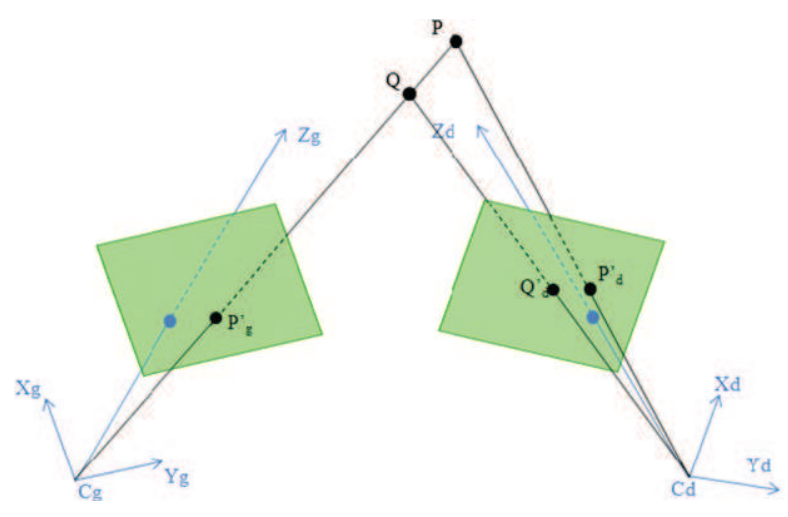

(a) stereovision principle (Fazzini [22])

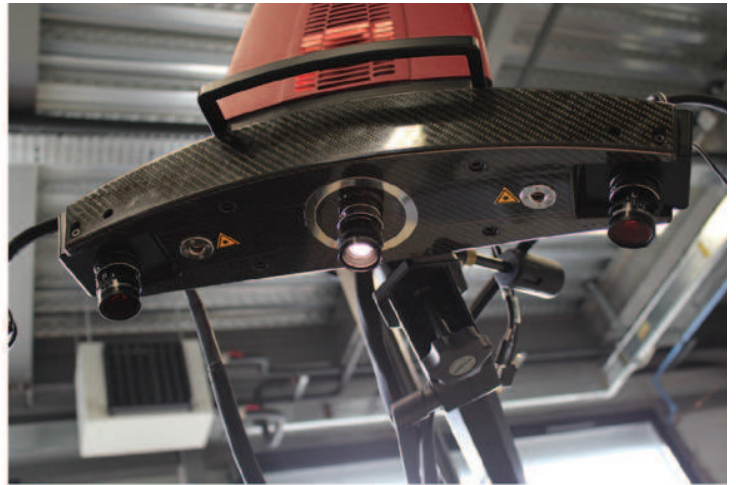

(b) ARAMIS acquisition system

Fig. 3. DISC technique.

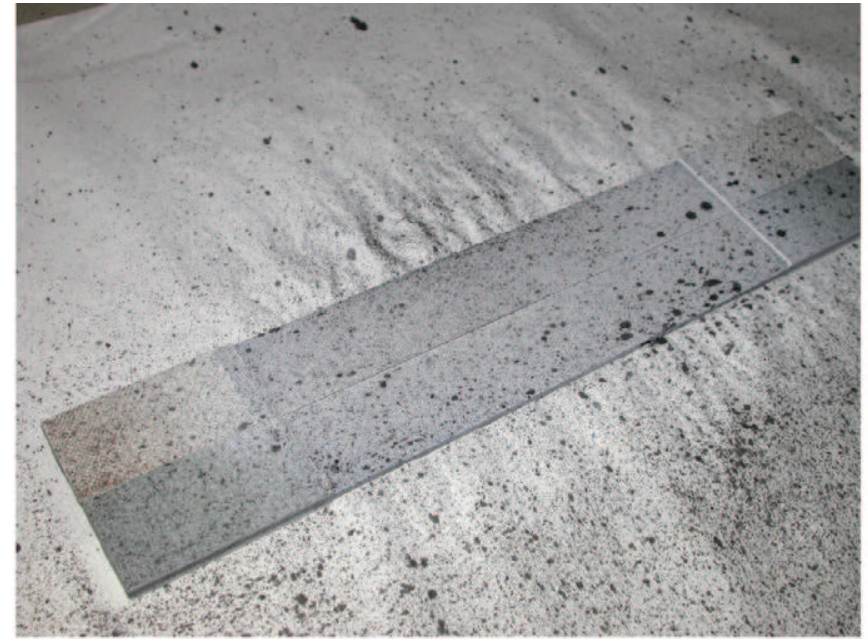

(a) sample paint

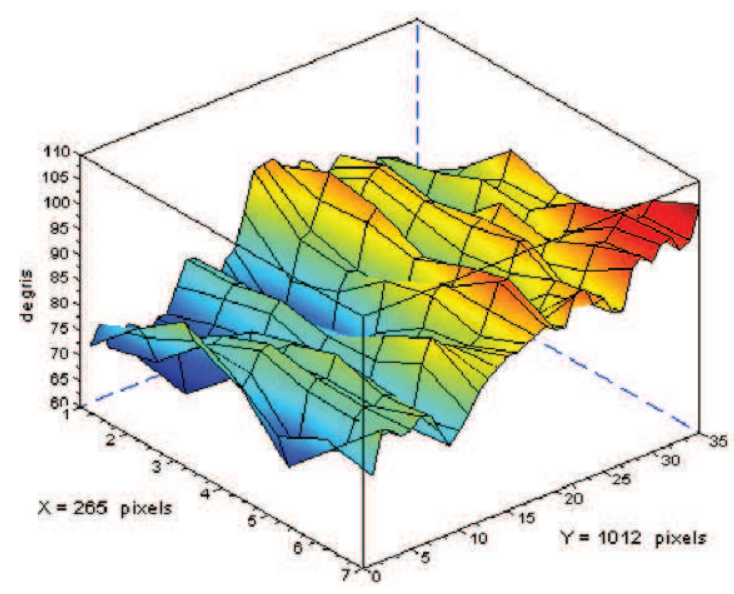

(c) spatial gray-level distribution

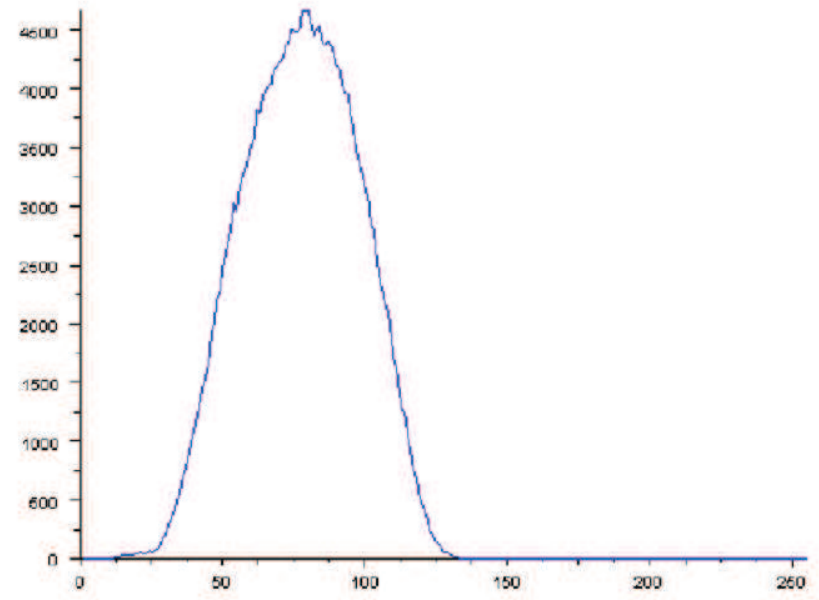

(b) gray-level distribution

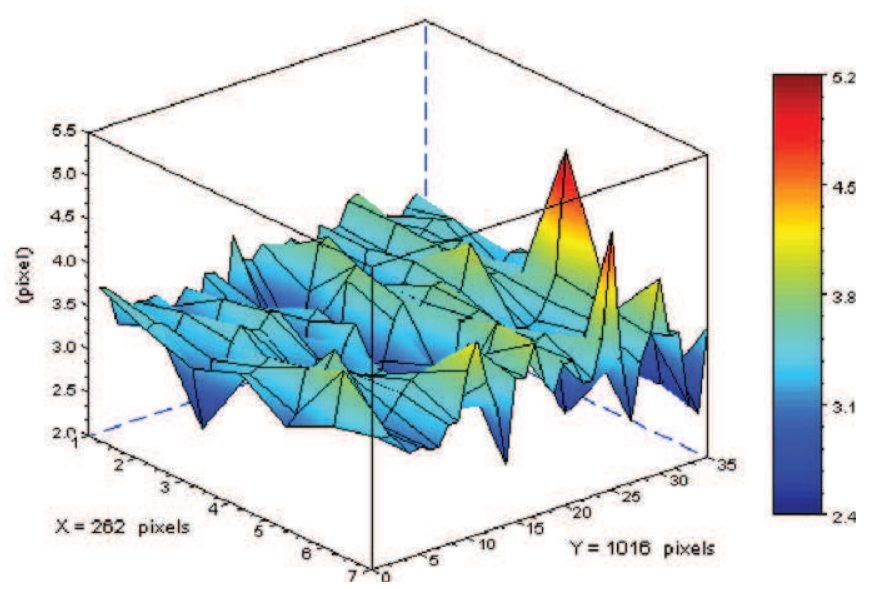

(d) speckle size distribution

Fig. 4. Artificial speckle,

tests, cyclic loads with unloading at various values of the failure strength were also achieved to highlight the material mechanical response at fixed damage state, and especially the degradation of elastic properties. 


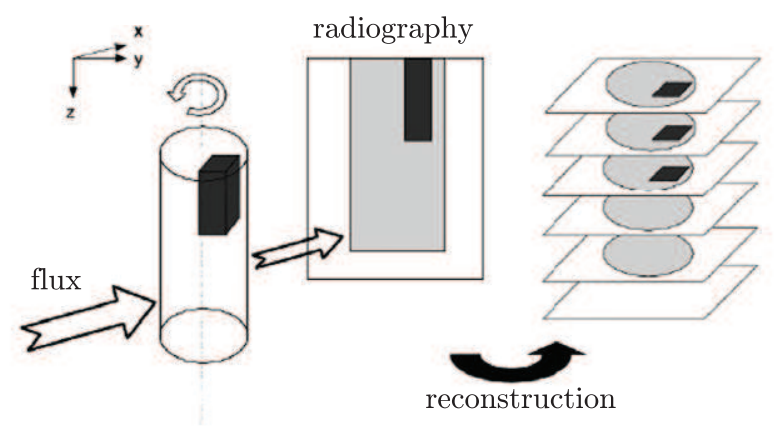

(a) principle (Carmona [35])
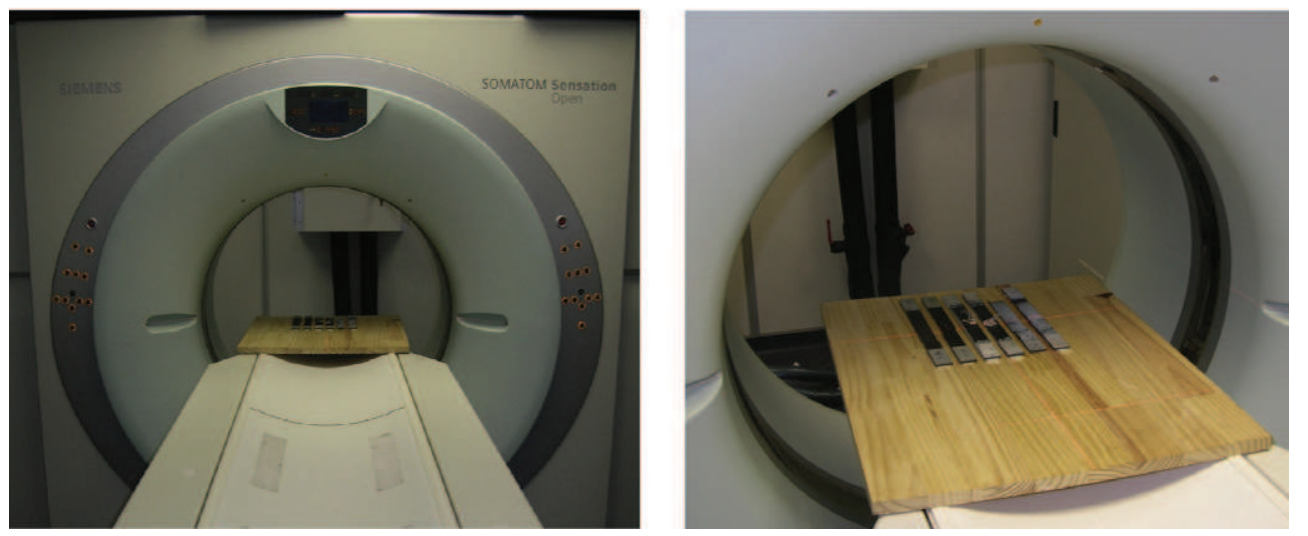

(b) Scanner SOMATOM ${ }^{\circledR}$ Sensation Open

Fig. 5. X-ray tomography technique.

\section{Experimental techniques}

\subsection{Digital image stereo-correlation technique}

Many methods provide displacements or strains maps on deformed surfaces (photoelasticity, moiré interferometry, holographic interferometry, Speckle interferometry, digital image correlation for instance; see review by Grédiac [10]). All these techniques can be distinguished through the kind of measures obtained (in-plane or both in-plane and out-of-plane displacements/strains) and the geometry of the observed surface (planar or not). Among optical methods, Digital Image Correlation (DIC) method is probably one of the most popular due to its implementation ease and development of commercial softwares [19]. From a pair of digital images recorded by a CCD camera in the initial and deformed states, one can compute by correlation the in-plane displacement field of any planar specimen under deformation (Fig. 2). Yet, the association of DIC with stereovision based on the use of two cameras considerably improves the technique by providing the 3-D displacement field and the surface strain field of any 3-D object ([20,21], Fig. 3). Two kinds of image matching are then performed: temporal pairing of two images from the same camera taken at two different times and a matching pair of stereoscopic images taken at the same time by the two cameras. Moreover, this so-called Digital Image Stereo-Correlation (DISC) technique is essential here for the simultaneous acquisition of kinematic and thermal fields. Indeed, the focal axis of the infrared camera needs to be centered and orthogonal to the sample (in the same manner as DIC camera). On the other hand, the position of DISC cameras is more flexible and then both measures can be simultaneously done during the test (Fig. 1).

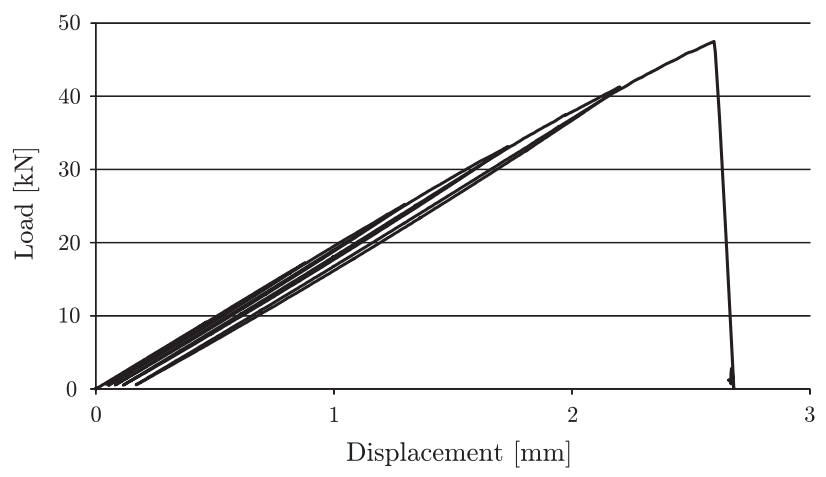

(a) type $\mathrm{A}$

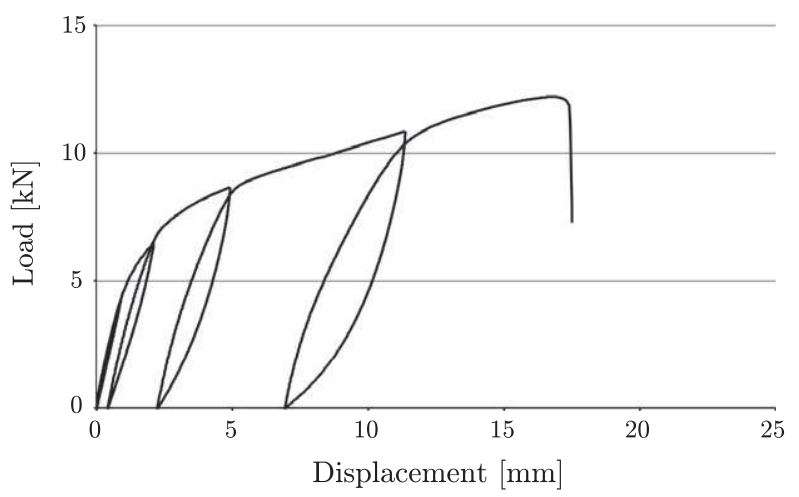

(b) type B

Fig. 6. Load-axial displacement curves (cyclic tests). 
(a) $\delta t=\frac{1}{152} s \simeq 0.006 s$

(b) $\delta t^{\prime}=\frac{31}{152} s \simeq 0.2 s$
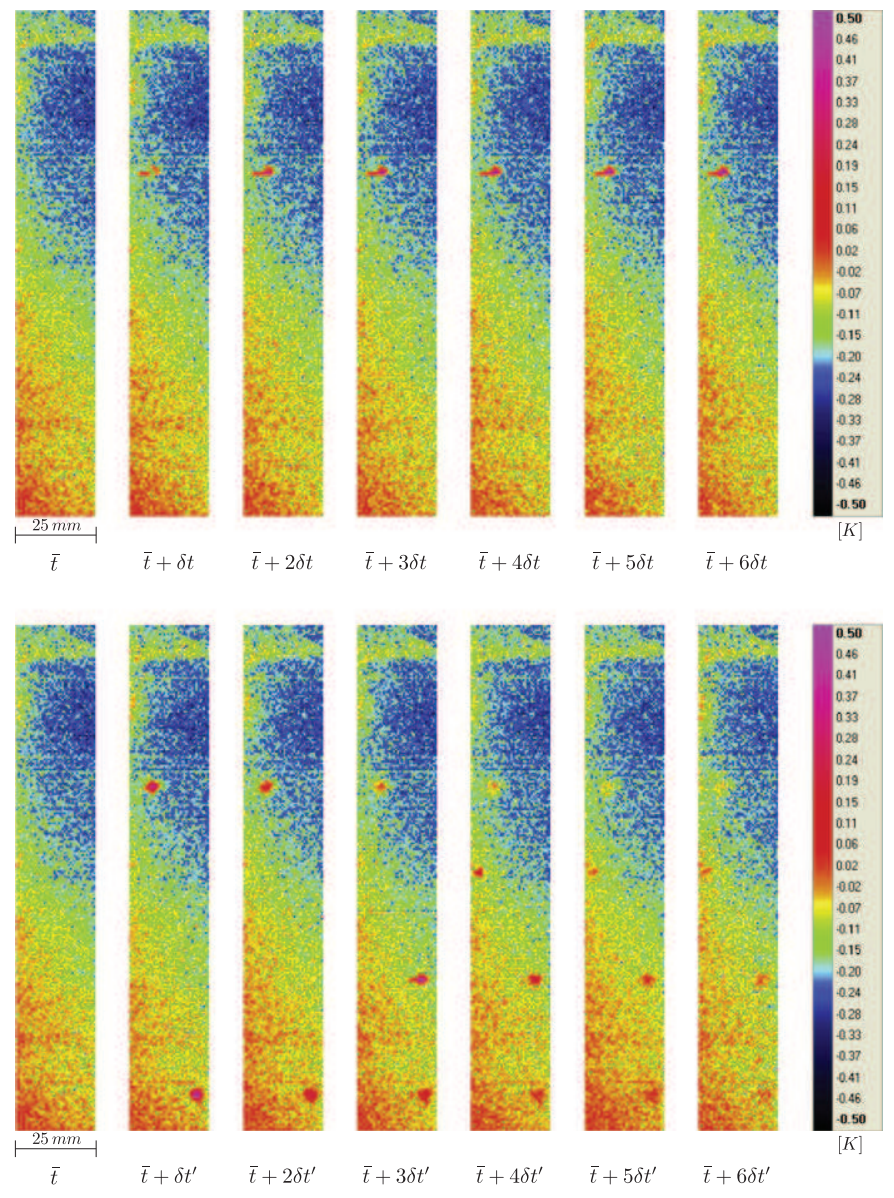

Fig. 7. Type A - consecutive mappings of the thermal field $\Delta T$ taken at regular intervals $\delta t$ and $\delta t^{\prime}$ from time $\bar{t}$ corresponding to about $50 \%$ of the yield stress.

The DISC system employed in our laboratory is ARAMIS 3D developed by GOM compagny [23]. CCD cameras allow a numerical image acquisition with a $1392 \times 1040$ pixels definition and the processing system is able to measure surface displacements of an object with a resolution of $5 \mu \mathrm{m}$ (respectively $15 \mu \mathrm{m}$ ) for in-plane (resp. out-of-plane) displacements.

Implementation of the DISC method requires following steps:

- Creation of artificial speckle - Displacements over the surface of the object are deduced from the gray-level analysis of an artifical speckle created with black and white paints (Fig. 4a); the speckle quality has been checked in order to ensure recognition by the CCD sensor of different gray levels and to allow an accurate tracking of each pixel during the deformation process (see automatic procedure developed by Fazzini [22], Fig. 4b-d);

- Calibration phase and lens adjustment - ARAMIS system can rapidly be calibrated by showing a planar pattern of the sample size put in different configurations [23]; moreover, distance between cameras is equal to $400 \mathrm{~mm}, 35 \mathrm{~mm}$ focal length has been chosen for cameras lens and the distance between the acquisition system and the specimen is around $700 \mathrm{~mm}$; resulting spatial resolution is then of about $80 \times 80 \mu \mathrm{m}^{2}$ (pixel size);

- Acquisition - Images are acquired from the beginning $(t=0)$ to the end of the test; according to the important data involved and related computational storage difficulties, the acquisition frequency is fixed here to one image per second; note also that only visible light has been used to avoid any influence on thermal data;

- Post-processing - Kinematic analysis is based on a total calculation mode (comparison of deformed configuration at time $t$ and reference state corresponding to the initial state $t=0$ ) and adjacent correlation windows of 21 pixels have been considered (see sensitivity analyses of Bornert et al. [24], Fazzini et al. [25]).

\subsection{Infrared thermography}

Infrared thermography is an optical measurement technique of the surface thermal field of a structure $[26,27]$. Obtaining the temporal evolution of the temperature field without contact, associated with versatility and easy handling, are some of the main advantages of this technique. Accordingly, infrared thermography has undergone a rapid growth over the last decade with a large scope of applications. In the field of mechanics, radiation measured may result from two origins:

- an external excitation (halogen lamps, xenon flash, lasers, etc.) whose effects are recovered in reflection or in transmission; a so-called active approach is particularly suitable for NonDestructive Testing (NDT) to reveal internal defects [28-30];

- and/or deformation of the material itself due to thermoelastic coupling and heat dissipations when the material is affected by irreversible mechanisms [13]; such passive approach is of particular interest for monitoring damage under stress with many applications in fatigue $[31,32]$; this kind of procedure has been employed in the present study.

Experimental device consists of a CEDIP ${ }^{\circledR}$ JADE III - FLIR ${ }^{\circledR}$ Titanium SC7000 retrofitted camera with InSb sensors (Fig. 1) [33]. Control of the camera and data recording are done with the associated software Altair, calibration operation is automatic. The focal plane 


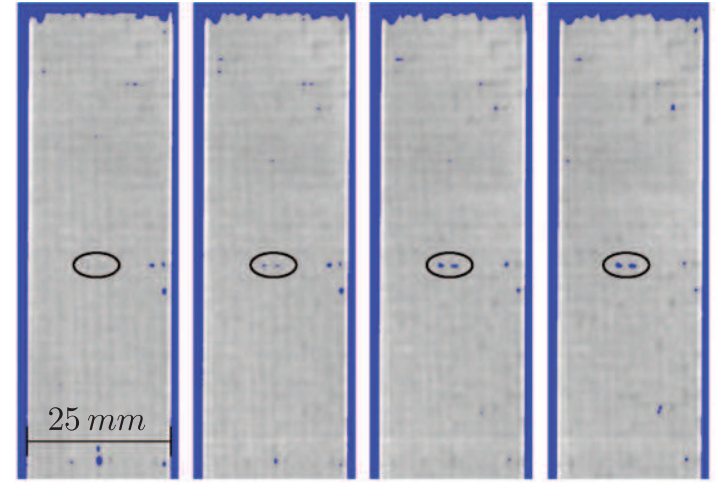

(a) type A

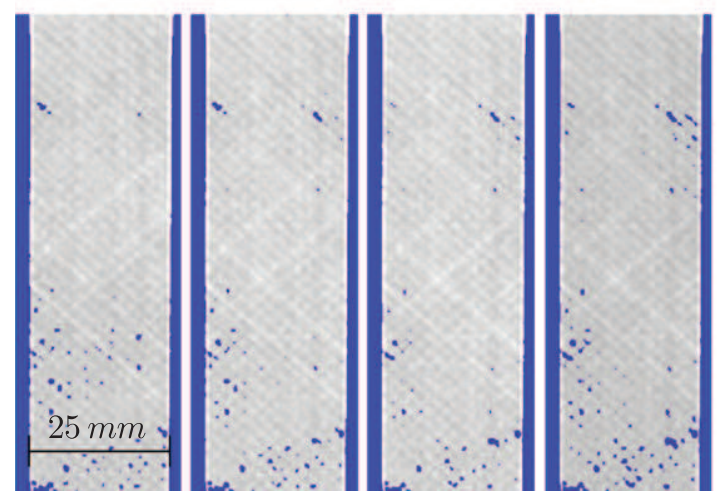

(b) type B

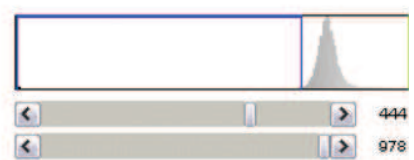

(c) threshold filter

Fig. 8. Coronal views in planes $(\mathbf{x}, \mathbf{y})$ of the density distribution at the middle depth of the samples - consecutive slices of 0.1 mm thickness (material is depited in gray, voids are depicted in blue according to threshold filter). (For interpretation of the references to colour in this figure legend, the reader is referred to the web version of this article.)

represents $320 \times 256$ pixels and spectral range is $[3.5,5] \pm 0.25 \mu \mathrm{m}$. The thermal resolution at $30^{\circ} \mathrm{C}$ is of $20 \mathrm{mK}$ and integration time is equal to $950 \mu \mathrm{s}$. For all tests, the maximum acquisition frequency has been considered ( $152 \mathrm{~Hz}$ for full frame). Once the camera is positioned so as to entirely cover the observed area and $50 \mathrm{~mm}$ lens adjusted, the distance to the specimen (here $0.95 \mathrm{~m}$ ) defines the pixel size, namely a rectangle of about $0.48 \times 0.58 \mathrm{~mm}^{2}$. All experiments were done under ambient conditions within a thermoregulated laboratory (external temperature of $25^{\circ} \mathrm{C}$ ) so as to limit surrounding influences.

In thermography, the transcription in temperature of the radiation captured by the camera requires the knowledge of the material emissivity (emission ratio between the material and a reference body said black body). A precise estimation of that parameter remains here quite difficult due to both the heterogenous character of the material and influence of the artificial speckle required for strain measurements. The present study is primarily focused on the development of thermal heterogeneities during the tests. For simplicity, uniform and constant value of emissivity corresponding to carbon (0.98) has then been considered. Moreover, a data processing after the acquisition phase provides the temperature variations fields $\triangle T=T-T_{0}$ over the sample, with $T$ the temperature field at time $t$ and $T_{0}$ the temperature field in the initial state $t=0$. Therefore, such relative analysis avoids the most disturbing effects, including environmental ones, and highlights the thermal events induced in the material.

\subsection{X-ray tomography}

X-ray tomography allows to study the internal structure of materials by means of their volumetric density distribution. It combines radiation measurement widely used for medical applications and mathematical reconstruction algorithm to provide 3D representations [34,35]:

- measuring the X-ray flux attenuation through an object leads to the 2D mapping of local absorption coefficient of the material that can be related to the material density; tomography involves gathering of these projection data from multiple directions whose number and spacing depend on the type of device and on the desired resolution; in the present case, acquisition sections correspond to axial planes $(\mathbf{x}, \mathbf{z})$ (see Section 2.1);

- data obtained from all sections can then be fed into a digital image processing system (reconstruction algorithms) to get the volumetric distribution of the specimen density (Fig. 5a); 2D rebuilt maps corresponding to sections different from those of the original measure (in our case for coronal views in planes $(\mathbf{x}, \mathbf{y}))$ can then be investigated.

In recent years, this technique has known a growing interest in materials science for non-intrusive studies of their fine microstructure (in particular heterogeneities, voids or inclusions), and that for different materials and at different scales depending on the equipment (micro-tomography, synchrotron, etc.). As for thermography, wide variety of applications can be found:

- for NDT, with aim of structural health investigation or quality control $[15,36]$; the present study is done within this framework;

- to follow the dynamic evolution of a microstructure under stress, when the size and acquisition time of tomographs are respectively compatible with the size of specimens and rates of physical phenomena $[37,38]$. 
TYPE A
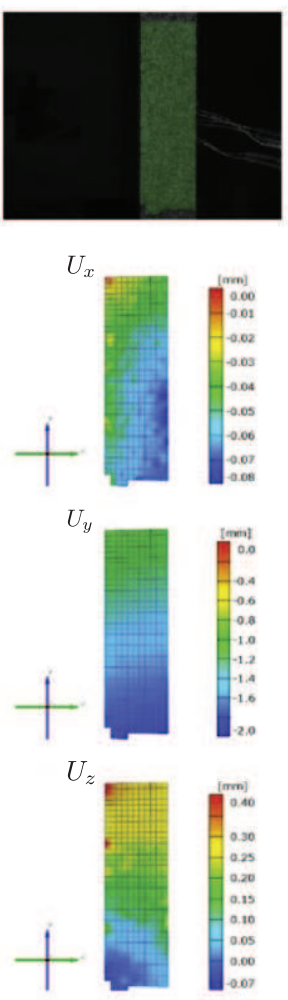

TYPE B

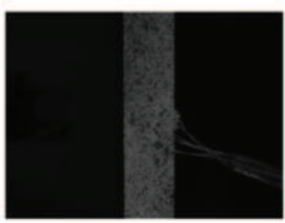

$U_{x}$
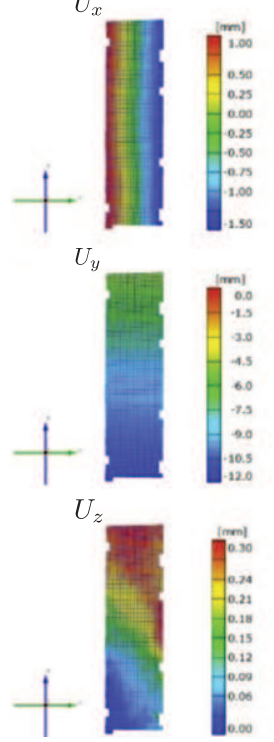

Anad : $47.363 \mathrm{kN}$

xial displacement : $2.548 \mathrm{~mm}$

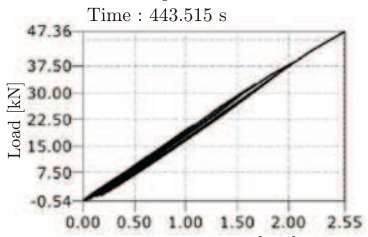

$\begin{array}{llllll}0.00 & 0.50 & 1.00 & 1.50 & 2.00 & 2.55\end{array}$
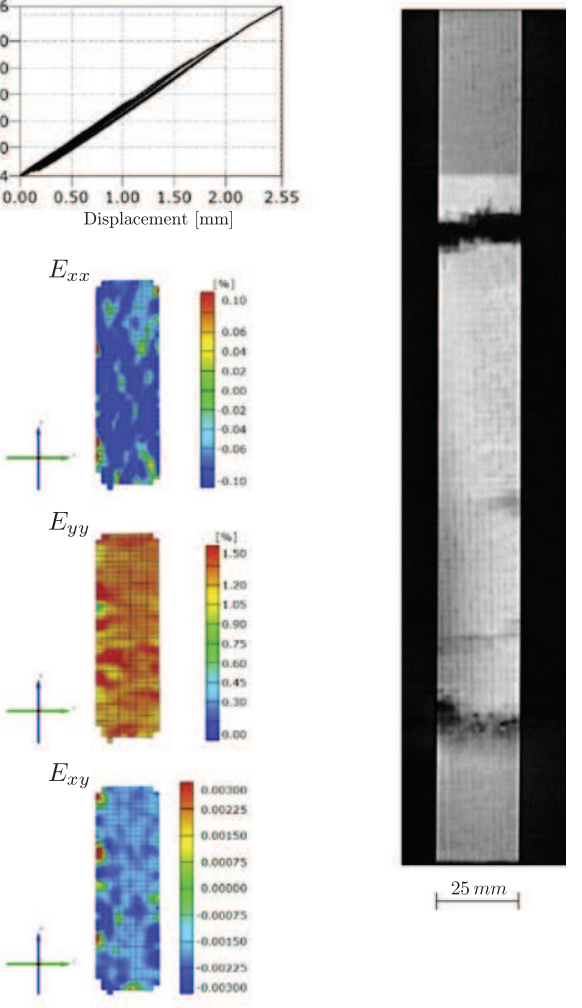

$25 \mathrm{~mm}$

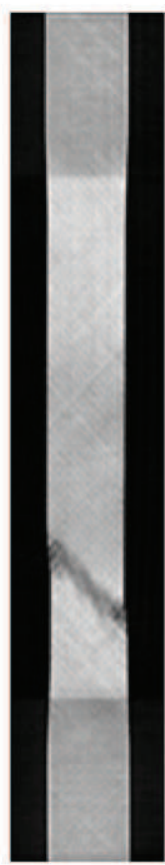

$25 \mathrm{~mm}$

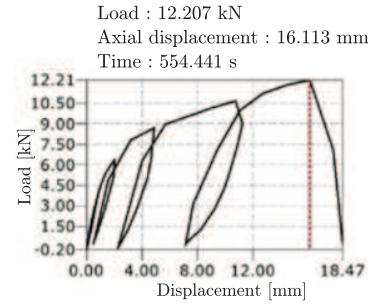

$E_{x x}$
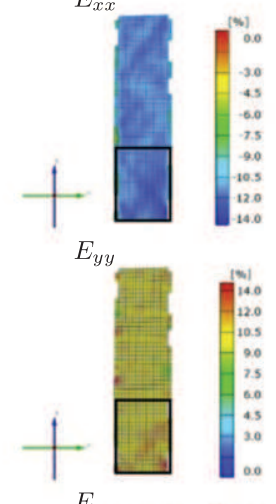

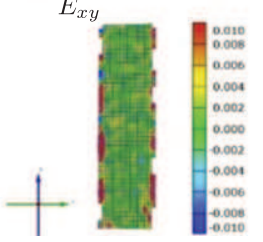

Fig. 9. Kinematic fields (displacements $\mathbf{U}=\left(U_{x}, U_{y}, U_{z}\right)$ and $(\mathbf{x}, \mathbf{y})$-plane strains $\left.\mathbf{E}=\left(E_{x x}, E_{y y}, E_{x y}\right)\right)$ close to failure and tomographic coronal view in plane $(\mathbf{x}, \mathbf{y})$ of the broken sample. 
(a) Type A

(b) Type B
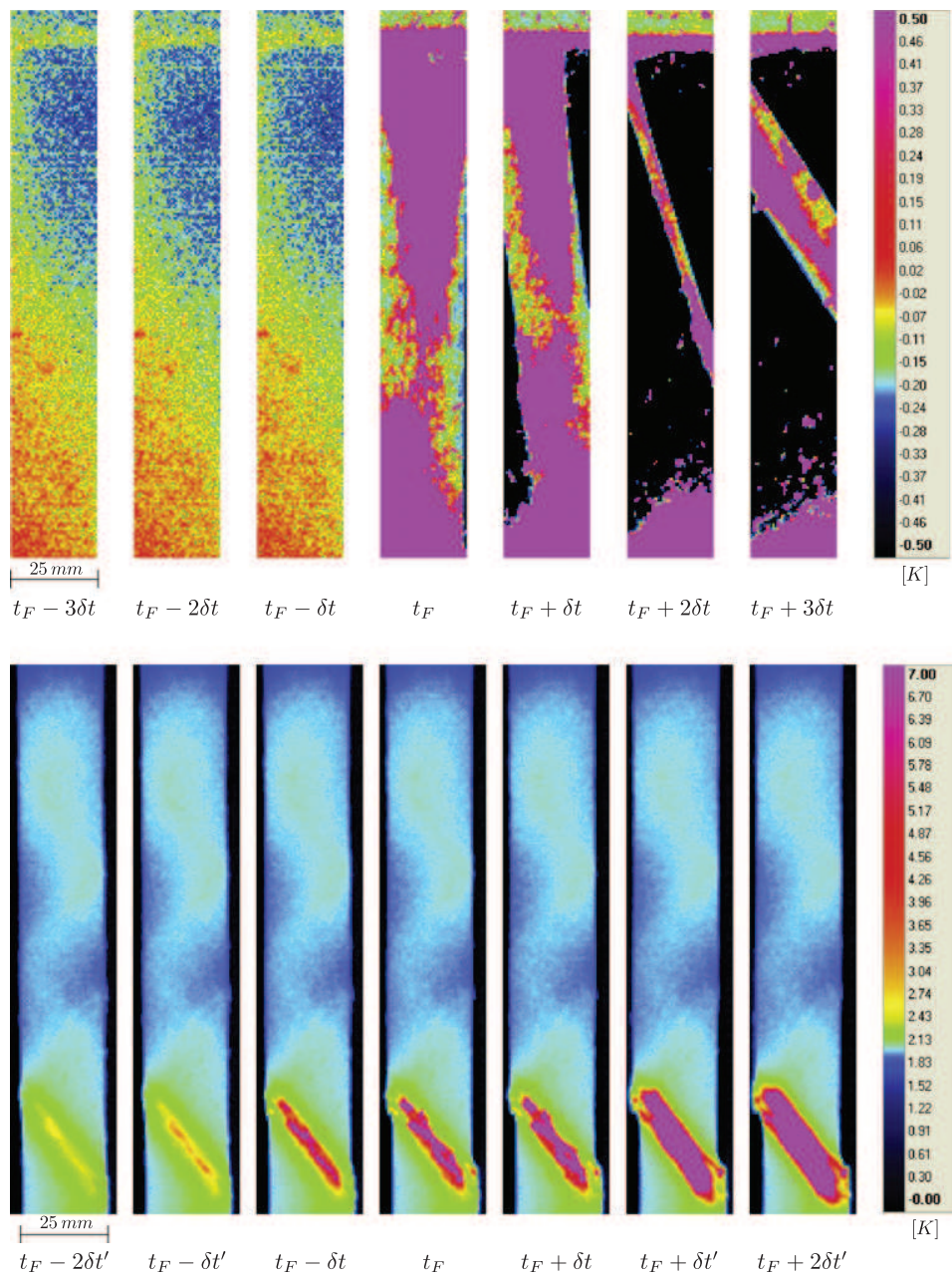

Fig. 10. Consecutive mappings of the thermal field $\Delta T$ around time $t_{F}$ corresponding to the failure point; time intervals considered are $\delta t=\frac{1}{152} \mathrm{~s} \simeq 0.006 \mathrm{~s}$ and $\delta t^{\prime}=\frac{31}{152} \mathrm{~s} \simeq 0.2 \mathrm{~s}$.

Tomographic sections were acquired on post-failure samples by the TOMO ADOUR compagny (Pau, France). A third-generation medical scanner has been used, namely SOMATOM ${ }^{\circledR}$ Sensation Open SIEMENS with maximum energy $140 \mathrm{keV}$ for a densimetric resolution of 0.1 (Fig. 5b). This device includes fan-beam X-ray generators and high definition ceramic sensors. Automatic calibration leads in the present case to a spatial resolution of about $0.1 \times 0.1 \times 0.1 \mathrm{~mm}^{3}$ (voxel size); in other words, 2D sections acquired have a thickness of $0.1 \mathrm{~mm}$. Post-processing is finally performed with the software Image [39].

\section{Results}

\subsection{Global response}

Before discussing the results of field measurements, we first examine the axial force-displacement response of materials provided by the testing machines:

- For type A samples (Fig. 6a), fibers oriented at $0^{\circ}$ are the most involved components; this leads to a macroscopic quasi linear elastic behavior typical of brittle damage; elastic properties are slightly degraded as shown by unloading-loading cycles and related to axial fiber breakage;

- The strong non-linearity of type B samples oriented at $45^{\circ}$ (Fig. 6b) corresponds to a ductile damage characterized by a more important degradation of mechanical properties (as evidenced by the decrease in slope apparent discharge); we note as well significant residual strains and hysteresis; such loading configuration much more involves the epoxy matrix part generating debonding surfaces (essentially at the fiber-matrix interfaces), friction on the lips of closed defects and viscous effects.

\subsection{Local damage phenomena}

The full-field acquisitions clearly improve such analysis by providing the spatial distributions of thermo-mechanical and physical quantities able to capture the local gradients. Indeed, the existence and growth of defects induce singularities in the measured fields [10].

The monitoring of kinematic and thermal measurements shows first the homogeneous response for low stress levels, and that for both types of samples. Indeed, strains distribution seems uniform up to an advanced level of the load (see Fig. 9). Note also that these results confirm the in-plane response of laminates (weak amplitude of the out-of-plane displacements). On the other hand, thermal data at the beginning of the test exhibit also an homogeneous evolution even if the influence of warm jaws (especially the lower one due to its mobility) leads to some weak dissymmetry in the distribution (see Figs. 7 and 10).

From about $30 \%$ of the yield stress and up to failure, one notes some thermal heterogeneities in the case of type A specimens re- 


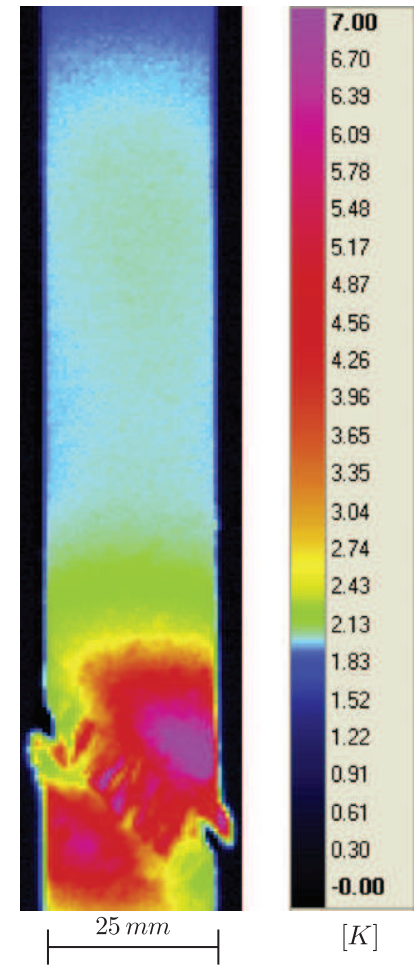

Fig. 11. Type B - mapping of the thermal field $\Delta T$ after failure $\left(t_{F}+40 \mathrm{~s}\right)$.

lated to fiber breakage. Fig. 7 shows a sequence of consecutive frames of the thermal mapping of the specimen from a time $\bar{t}$ corresponding to about $50 \%$ of the yield stress. Heating are put in evidence through colored spots on the infrared pictures. The dissipation induced by these local events is visible for a few seconds due to the thermal inertia of the material. These spots have a random location distribution within the sample and appear more frequently as load increases. It should be added that popping sounds characteristics of fiber failure can also be heard during the test, and this especially also as we get close to failure. However, these thermal and sound events are interrupted by unloadingloading cycles and start again when the stress level exceeds the tension achieved in the previous cycle. Regarding type B samples, local thermal phenomena are not observed. For damage mechanisms involved, in this case mostly fiber-matrix debonding, lower energy is locally required and dissipative behavior appears as much more diffuse within the material (at least up to the localization phase, see Section 4.3).

The densimetric field analysis also demonstrates the loss of cohesion induced by damage. Actually, the presence of defects is observable on tomographic sections through the contrast of gray levels, and hence density, between the defects (zero density) and virgin material (density of around 1.5 due to the components density and fiber ratio, Section 2.1). To this end, we present in Fig. 8 consecutive coronal views (2D rebuilt maps in planes $(\mathbf{x}, \mathbf{y})$ ) taken at the middle depth of specimen; according to the voxel size, each slice has a thickness of $0.1 \mathrm{~mm}$. Areas represented are not concerned by the macroscopic failure in order to focus on the damage features; in addition, a threshold filter corresponding to $5 \%$ of the gray scale distribution has been applied to highlight the damaged zones (Fig. 8c).

For all samples, we note again that damage is randomly distributed in the whole volume of the material, that is both in the coronal planes (which stands in agreement with thermal events observed for type A samples) and in the thickness. In particular, Fig. 8a illustrates the development of voids within the laminate thickness. In quantitative terms, type B samples appear slightly more affected by damage compared to type A; this corroborates the more important degradation of axial elastic properties of type B samples observed on Fig. 6. Although the measurement resolution cannot define precisely the geometry of debonding zones, there is still a very much preferred damage orientation depending on the type of specimens:

- type A specimens: debonding zones stand primarily in the direction orthogonal to the axis $\mathbf{y}$ of loading due to damage by $0^{\circ}$ fibers breakage (Fig. 8a);

- type B specimens: debonding zones are rather inclined at around $45^{\circ}$ with loading axis $\mathbf{y}$, resulting from fiber-matrix debonding mechanisms (Fig. 8b).

These results thus illustrate the interaction between the initial (structural) anisotropy given by the composite structure and the load-induced anisotropy of damage.

\subsection{Localization and macroscopic failure}

Full-field live measurement techniques were also useful to achieve tracking of the laminates macroscopic failure.

In the case of type A samples with purely brittle behavior, no forewarning sign of failure could be demonstrated with DISC technique. Strain heterogeneities remain in the measurement noise and kinematic fields appear as homogeneous up to the final stage

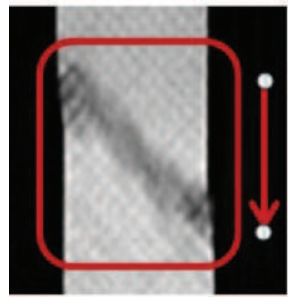

$25 \mathrm{~mm}$

(a)

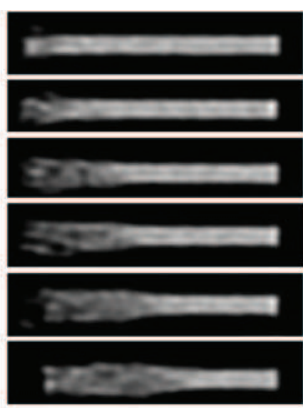

$25 \mathrm{~mm}$

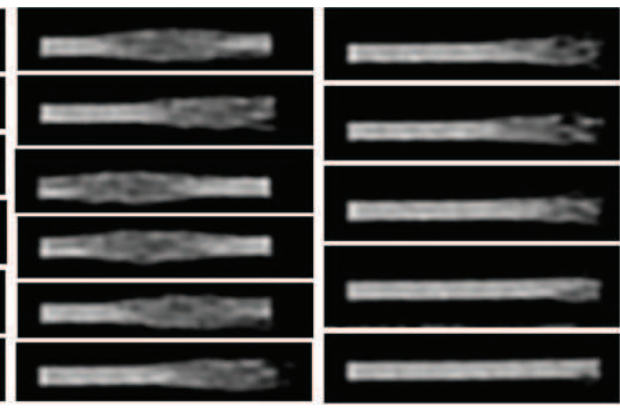

(b)

Fig. 12. Type B - densimetric field along the macro-defect: (a) browsing zone and direction defined on coronal view in plane (x,y), (b) related consecutive axial views in planes $(\mathbf{x}, \mathbf{z})$ of the covered area. 
of testing even in the macroscopic failure zone of the material (Fig. 9a). Infrared imaging confirms also the brittle character of type A specimens. We observe on Fig. 10 a sequence of consecutive frames around the failure point $t_{F}$; picture at time $t_{F}$ corresponds to the first thermal frame captured after the peak stress. For axis load (type A), failure phenomena and related movement of the broken sample can be seen clearly. Although the acquisition rate of the thermal camera (frequency of $152 \mathrm{~Hz}$ ) is much more bigger than DISC cameras (frequency of $1 \mathrm{~Hz}$ ), thermography however cannot capture the development of such brittle mechanism. Indeed, even with the smallest interval between frames $\left(\delta t=\frac{1}{152} \mathrm{~s} \simeq 0.006 \mathrm{~s}\right)$, failure phenomena induces a sudden jump in the thermal field evolution: the thermal field is homogeneous with some local spots just before failure (at time time $t_{F}-\delta t$ on Fig. 10a), while the sample is completely broken just after the peak stress (at time $t_{F}$ ). At last, consecutive frames (for instance at times $t_{F}+2 \delta t$ or $t_{F}+3 \delta t$ ) clearly show the broken sample flying out from the experimental device and carbon particles dissociated from the material.

For type B however, the ductile damage behavior induces a localization phase before failure. Indeed, transversal $\left(E_{x x}\right)$ and longitudinal $\left(E_{y y}\right)$ strains exhibit a localized distribution very close to the failure point through a classical cross form oriented at around $45^{\circ}$. One line of that cross corresponds thereafter to the macrocrack of the specimen (Fig. 9b). Thermal measurements corrolate also this observation (Fig. 10b). From around $90 \%$ of the peak stress, one sees indeed a warmer area in the form of a line inclined at $45^{\circ}$ with loading axis $\mathbf{y}$ reflecting the damage accumulation associated with strain localization. Compared to the final temperature rise induced in the type A samples, heating of the localized area is very important due to multiple failure mechanisms involved (see Section 4.4). Regarding the techniques, the acquisition frequency of thermography allows it to better monitor the emergence and growth of the localized heating zone before the failure point $t_{F}$ (see on Fig. $10 \mathrm{~b}$ thermal maps at $t_{F}-2 \delta t^{\prime}$ or $t_{F}-\delta t^{\prime}$ with $\delta t^{\prime}=\frac{31}{152} \mathrm{~s} \simeq 0.2 \mathrm{~s}$ ). Note finally in this case that the movement of the sample at the failure point $t_{F}$ is much lower than for type A. As evidenced on Figs. 9b, 11 and 12, section of the specimen is not completely separated by off-axis load, fibers still maintain some cohesion of the whole.

\subsection{Post-mortem observations}

Direct observation of fracture surface corroborates the influence of the orientation of load with initial anisotropy on the degradation mechanisms. For type A specimens, the macroscopic fracture is orthogonal to the tension axis and clean, in agreement with the failure of all $0^{\circ}$ fibers (Fig. 9a). In the case of type B however, fiber-matrix debonding and delamination between the plies lead to fracture. Heat dissipation is even so high that fibers pullingout can be seen on thermal frames (Fig. 11). Consecutive axial tomographic views in the macro-defect area make also clearly appear the plies delamination in the laminate thickness. This mechanism follows an inclined line in the coronal plane, corresponding to the localized heating zone (Figs. 10b and 12).

\section{Conclusion and perspectives}

In recent years, optical techniques have led to major advances in experimental mechanics, especially in the field of material characterization. Their application to damage investigation in CFRP laminates has been addressed in the present work. The main contribution of the study is to combine three kinds of full-field measurement techniques (DISC, infrared thermography and X-ray tomography). Kinematic, thermal and densimetric fields are relevant indicators of degradation process and heterogeneities detected in their respective data provide different demonstrations of same damage features (location distribution of defects, localization phenomenon, failure mode, influence of the initial anisotropy, etc.).

More generally, this work demonstrates the feasibility of coupled measures with commercial systems. It shows at the same time the interest of their combination since some techniques are better suited for some phenomena (for instance local fiber breakage captured by infrared thermography). This is therefore an interesting step forward the development of these investigation approaches for composite materials and structures.

If at first the focus was put on qualitative aspects, we should now go further in examining the quantitative evaluation of processes involved. Considering their related rate, it would also be interesting to use high speed camera to refine the observation, especially for strain measurements in the case of brittle failure. This would help in defining the most appropriate technique to capture every aspect of the damage process.

\section{Acknowledgements}

Authors fully acknowledge the staffs of the Composites Research Center of Tarbes, of the NIMITECH ETUDES company, of the Engineering Center of Mechanics, Materials and Surfaces of the National Engineering School of Tarbes and of the TOMO ADOUR company for their technical support and helpful contribution to this work. Special thanks also to Marie-Laetitia Pastor from Clément Ader Toulouse Institute - Technologic Institute of Tarbes for useful discussions.

\section{References}

[1] Ladeveze P, Lubineau G, Marsal D. Towards a bridge between the micro- and mesomechanics of delamination for laminated composites. Compos Sci Technol 2006;66:698-712.

[2] Dzenis Y, Qian J. Analysis of microdamage evolution histories in composites. Int J Solids Struct 2001;38:1831-54.

[3] Mizutani Y, Nagashima K, Takemoto M, Ono K. Fracture mechanism characterization of cross-ply carbon-fiber composites using acoustic emission analysis. NDT\&E Int 2000;33:101-10.

[4] Bouazzaoui RE, Baste S, Camus G. Development of damage in a 2D woven C/SiC composite under mechanical loading: II. Ultrasonic characterization. Compos Sci Technol 1996;56:1373-82.

[5] Steiner K, Eduljee R, Huang X, Jr JG. Ultrasonic NDE techniques for the evaluation of matrix cracking in composite laminates. Compos Sci Technol 1995;53:193-8.

[6] Abry J, Bochard S, Chateauminois A, Salvia M, Giraud G. In situ detection of damage in CFRP laminates by electrical resistance measurements. Compos Sci Technol 1999;59:925-35.

[7] Wen J, Xia Z, Choy F. Damage detection of carbon fiber reinforced polymer composites via electrical resistance measurement. Composites Part B 2011;42:77-86.

[8] Yashiro S, Takeda N, Okabe T, Sekine H. A new approach to predicting multiple damage states in composite laminates with embedded FBG sensors. Compos Sci Technol 2005;65:659-67.

[9] Zhou G, Sim L. Evaluating damage in smart composite laminates using embedded EFPI strain sensors. Opt Lasers Eng 2009;47:1063-8.

[10] Grédiac M. The use of full-field measurement methods in composite material characterization: interests and limitations. Composites Part A 2004;35:751-61.

[11] Colin de Verdiere M, Pickett A, Skordos A, Witzel V. Evaluation of the mechanical and damage behaviour of tufted noncrimped fabric composites using full field measurements. Compos Sci Technol 2009;69:131-8.

[12] Devivier C, Pierron F, Wisnom M. Damage detection in composite materials using deflectometry, a full-field slopemeasurement technique. Composites Part A 2012;43:1650-66.

[13] Chrysochoos A. Infrared thermography, a potential tool for analysing the material behaviour. Mécanique Ind 2002;3:3-14.

[14] Meola C, Carlomagno G. Impact damage in GFRP: new insights with infrared thermography. Composites Part A 2010;41:1839-47.

[15] Bayraktar E, Antolovich S, Bathias C. New developments in non-destructive controls of the composite materials and applications in manufacturing engineering. J Mater Proc Technol 2008;206:30-44.

[16] Salvo L, Cloetens P, Maire E, Zabler S, Blandin J, Buffière J, et al. X-ray microtomography: an attractive characterization technique in materials science. Nucl Instr Meth Phys Res B 2003;200:273-86. 
[17] Bodelot L, Charkaluk E, Sabatier L, Dufrénoy P. Experimental study of heterogeneities in strain and temperature fields at the microstructural level of polycrystalline metals through fully-coupled full-field measurements by digital image correlation and infrared thermography. Mech Mater 2011;43:654-70.

[18] Dumoulin S, Louche H, Hopperstad O, Borvik T. Heat sources, energy storage and dissipation in high-strength steels: experiments and modelling. Eur J Mech A/Solids 2010;29:461-74.

[19] fSutton M, McNeill S, Helm J, Chao Y. Advances in two-dimensional and three-dimensional computer vision. Photomech Topics Appl Phys 2000;77:323-72.

[20] Orteu J. 3-D computer vision in experimental mechanics. Opt Lasers Eng 2009;47:282-91.

[21] Perret A, Mistou S, Fazzini M, Brault R. Global behaviour of a composite stiffened panel in buckling. Part 2: experimental investigation. Compos Struct 2012;94:376-85.

[22] Fazzini M. Développement de méthodes d'intégration des mesures de champs. Ph.D. thesis. Institut National Polytechnique de Toulouse; 2009.

[23] GOM, Aramis software; 2006. <http://www.gom.com/3D-software/aramissoftware.html, URL http://www.gom.com/3d-software/aramis-software>.

[24] Bornert M, Brémand F, Doumalin P, Dupré J, Fazzini M, Grédiac M, et al. Assessment of digital image correlation software packages. Exp Mech 2009;49:353-70.

[25] Fazzini M, Mistou S, Dalverny O, Robert L. Study of image characteristics on digital image correlation error assessment. Opt Lasers Eng 2010;48: 335-339.

[26] Maldague X. Theory and practice of infrared technology for nondestructive testing. Wiley-Interscience; 2001.

[27] Walker N. Infrared thermography handbook - principles and practice, vol 1. The british Institute of non-destructive testing; 2004.

[28] Dattoma V, Marcuccio R, Pappalettere C, Smith G. Thermographic investigation of sandwich structure made materials. NDT\&E Int 2001;34:515-20.
[29] Garnier C, Pastor M, Eyma F, Lorrain B. The detection of aeronautical defects insitu on composite structures using nondestructive testing. Compos Struct 2011;93:1328-36.

[30] Sakagami T, Kubo S. Applications of pulse heating thermography and lock-in thermography to quantitative nondestructive evaluations. Inf Phys Technol 2002;43:211-8.

[31] Garnier C, Lorrain B, Pastor M. Impact damage evolution under fatigue loading by infrared thermography on composite structures. In: Int Conf Exp Mech ICEM 14, Poitiers (France); 2010.

[32] Steinberger R, Valadas Leitao T, Ladstätter E, Pinter G, Billinger W, Lang R. Infrared thermographic techniques for non-destructive damage characterization of carbon fibre reinforced polymers during tensile fatigue testing. Int J Fatigue 2006;28:1340-7.

[33] FLIR, Technical specifications - titanium series. Tech. Rep.; 2010. <http:// www.infraredresearchcameras.com>.

[34] Bossi R, Friddell K, Lowrey A. Nondestructive testing of fiber-reinforced plastic composites. chap. Computed tomography. London: Elsevier Applied Science Publishers; 1990. p. 201-52.

[35] Carmona V. Etude de l'endommagement de matériaux composites par tomographie $\mathrm{X}$ et émission acoustique. Ph.D. thesis. Institut National des Sciences Appliquées de Lyon; 2009.

[36] Schilling P, Karedla B, Tatiparthi A, Verges M, Herrington P. X-ray computed microtomography of internal damage in fiber reinforced polymer matrix composites. Compos Sci Technol 2005;65:2071-8.

[37] Hufenbach W, Böhm R, Gude M, Berthel M, Hornig A, Rusevskis S, et al. A test device for damage characterisation of composites based on in situ computed tomography. Comp. Sci. Tech. 2012;72:1361-7.

[38] Moffat A, Wright P, Buffière J, Sinclair I, Spearing S. Micromechanisms of damage in 0 splits in a $(90 / 0)$ s composite material using synchrotron radiation computed tomography. Scripta Mater 2008;59:1043-6.

[39] Ferreira T, Rasband W. The ImageJ user guide. Tech. Rep.; 2010. <http:// rsbweb.nih.gov/ij/>. 